\title{
A Combinatorial Approach towards Adaptability of 22 Functional Cas12a Orthologs for Nucleic Acid Detection in Clinical Samples
}

Long T. Nguyen ${ }^{1}$, Nicolas C. Macaluso ${ }^{1}$, Piyush K. Jain ${ }^{1,2 *}$

${ }^{1}$ Department of Chemical Engineering, University of Florida, Gainesville FL, USA

${ }^{2}$ UF Health Cancer Center, University of Florida, Gainesville FL, USA

*Corresponding author: Jainp@ufl.edu 
medRxiv preprint doi: https://doi.org/10.1101/2021.07.21.21260653; this version posted July 22, 2021. The copyright holder for this preprint (which was not certified by peer review) is the author/funder, who has granted medRxiv a license to display the preprint in perpetuity. It is made available under a CC-BY-NC-ND 4.0 International license .

\begin{abstract}
Reliable, efficient, and cheap detection of infectious diseases, especially in the wake of the SARS-CoV-2 pandemic, is of increasing importance. CRISPR/Cas systems have the capabilities to be optimized for this purpose. There is a broad diversity among Cas12a nucleases with immense detection capability, but only a few have been purified and studied biochemically. Here we present the investigation of 22 Cas12a orthologs, with a focus on their cis- and trans-cleavage activity, and thermal stability in combination with non-canonical crRNAs. We noticed that some non-canonical crRNA:Cas12a effector complexes outperformed its corresponding wild-type crRNA:Cas12a complex in transcleavage assays. In particular, TsCas12a, ErCas12a, and ArCas12a showed an increase in thermal stability in binary complex compared to its wild-type structure and apo form. Moreover, Cas12a was observed to have the ability to recruit segments of truncated crRNAs which has the potential for further applications. We also discovered that ErCas12a, BsCas12a, BoCas12a, and TsCas12a possess robust trans-cleavage activity with a shorter PAM sequence requirement. Finally, we applied these effector complexes to discriminately detect SARS-CoV-2 and its B.1.1.7 lineage in clinical nasopharyngeal swabs, saliva samples, and tracheal aspirates. Our findings further expand the toolbox for next-generation CRISPR-based diagnostics.
\end{abstract}

\title{
Introduction
}

With millions of people being negatively impacted by the COVID-19 pandemic, it has never been more urgent to emphasize the importance of surveillance testing, specifically to monitor the possibility of future infectious outbreaks $(1,2)$. This early action not only provides information about public health but also allows for policymakers to quickly implement strategies based on scientific data. As a result, early detection plays a crucial role in expediting this process. Since the COVID-19 pandemic started in late 2019, scientists around the globe have been developing rapid and sensitive diagnostic kits based on CRISPR technologies (3-9). In particular, Class 2 type V and VI single effector Cas12a, Cas12b, and Cas13a have been increasingly harnessed to detect SARS-CoV-2 with high sensitivity comparable to the traditional RT-qPCR tests $(3,4,6,8,10-16)$. CRISPR-based detection works by triggering Cas protein nonspecific collateral endonuclease cleavage, or trans-cleavage, of reporters, once a crRNA:Cas12a effector complex is bound to its target nucleic acid.

Since its discovery, the cis-cleavage properties of several Cas12a orthologs have been studied for gene editing. LbCas12a, AsCas12a, and FnCas12a are the prominent candidates that have been widely utilized for this purpose $(5,17-24)$. There is a big diversity among Cas $12 \mathrm{a}$, but only a few have been purified and studied biochemically. Cas12a effectors have been of special interest to us as a limited number were discovered to have robust trans-cleavage activity suitable for nucleic acid detection (LbCas12a and AsCas12a). Although optimized for unique situations, there is much room for improvement towards universally applicable assay formulation. Therefore, it is desired to expand the current diagnostic toolbox with the investigation into the trans-cleavage activity of other Cas12a orthologs. 
medRxiv preprint doi: https://doi.org/10.1101/2021.07.21.21260653; this version posted July 22, 2021. The copyright holder for this preprint (which was not certified by peer review) is the author/funder, who has granted medRxiv a license to display the preprint in perpetuity. It is made available under a CC-BY-NC-ND 4.0 International license .

We herein present the study of 22 Cas12a $(20,21,24,25)$, specifically their cis-cleavage, trans-cleavage activity, and thermal stability in combination with non-canonical crRNAs. We observed that when these Cas12a effectors complex with some non-canonical crRNAs through combinatorial assays, their trans-cleavage activity outperformed wildtype crRNA. Also, TsCas12a, ErCas12a, and ArCas12a showed an increase in thermal stability in binary complex compared to its wild-type structure and apo form. These phenomena facilitate our further understanding of the interactions between crRNA and Cas $12 a$ and enable us to identify an engineerable region of the crRNA scaffold. Interestingly, we found that Cas12a can recruit segments of truncated crRNAs, and can form a functional catalytic complex with a potential for further applications.

Regarding the nucleic acid detection capability of various Cas $12 a$ orthologs, we discovered that ErCas12a, BsCas12a, BoCas12a, and TsCas12a possess robust transcleavage activity with a shorter protospacer adjacent motif (PAM) sequence requirement. When complexed with some non-canonical crRNAs, their detection outperformed wildtype crRNA. Finally, we applied the optimal pairs to differentiate SARS-CoV-2 alpha or B.1.1.7 lineage in clinical nasopharyngeal swabs, saliva samples, and tracheal aspirates. Along with crRNA manipulation, biodiverse Cas12a orthologs expand the toolbox for nextgeneration diagnostics. We named our approach of combining different orthologs of crRNA/Cas as cCRISPR (combinatorial CRISPR).

\section{Results}

\section{Trans-cleavage performance of 22 Cas12a orthologs}

Inspired by previous studies on Cas12a orthologs with diverse applications, we sought to further investigate a collection of these Cas12a proteins and analyze their phylogenetic relevance and direct repeat sequences. We were interested in the conformational adaptability of crRNA and Cas12a, particularly how their non-canonical binary complexation affects their functionality. 23 Cas $12 a$ with highly similar corresponding mature crRNA were selected for this study. As reported by Zetsche et. al. and Teng et. al., many of these functional Cas12a proteins share the same mature crRNAs but do not necessarily have significant percent identity in their amino acid sequences, confirmed by phylogenetic analyses (Fig. 1a and Supplementary Fig. S1) (21, 24). Interestingly, these mature crRNA differ in sequences between the stem left and stem right (Fig. 1b). Considering the protein pre-processing property(26), nine groups of distinct mature crRNAs were identified and proceeded with the study. We expressed and purified 23 Cas12a proteins by subcloning human codon-optimized gene fragments into a bacterial expression plasmid and transformed them into E. coli competent cells (Supplementary Fig. S2).

We proceeded to investigate the performance of these Cas12a proteins by carrying out cis-cleavage and trans-cleavage reporter assays via complexing 9 distinct crRNAs to 23 Cas12a proteins in the presence of ssDNA and ssRNA sequence-specific reporters. Among 23 Cas12a proteins, many of them are thought to prefer T-rich PAM sequences 
medRxiv preprint doi: https://doi.org/10.1101/2021.07.21.21260653; this version posted July 22, 2021. The copyright holder for this preprint (which was not certified by peer review) is the author/funder, who has granted medRxiv a license to display the preprint in perpetuity. It is made available under a CC-BY-NC-ND 4.0 International license .

although some appeared to have been studied without an identified PAM. We designed guide RNAs targeting a dsDNA region within the gene encoding the Green Fluorescent Protein (GFP) with a PAM sequence TTTN. Through in vitro cis-cleavage assay, we discovered that many of the Cas 12 a effector proteins can adopt crRNA orthologs derived from 23 examined species, except for LpCas12a which failed to verify its function with these assays. Interestingly, we found that the cis-cleavage activity of a majority of Cas12a proteins was enhanced when complexed with non-canonical crRNAs and can potentially be applied for gene editing applications (Fig. 1c and Supplementary Fig. S5).

We performed trans-cleavage assays with a variety of reporters (TTTT, TTATT, CCGCC, rUrUrUrUrU, rUrArUrArU), and unanimously found the highest fluorescence signal with the poly-T sequence reporter. Consistent with the literature, we observed higher cleavage rates with DNA reporters when compared with an RNA reporter (Fig. 1d-f and Supplementary Fig. S3). Some orthologs demonstrated noticeable RNA cleavage activity (Supplementary Fig. S4). Of the examined effectors, BoCas12a, BsCas12a, ErCas12a, and TsCas12a exhibited high trans-cleavage activity comparable to the widely used LbCas12a and AsCas12a. Notably, the majority of Cas12a trans-cleavage activity was enhanced when complexed with non-canonical crRNAs (Fig. 1d-f and Supplementary Fig. S3, S4). The same phenomenon was observed via in vitro cis-cleavage assay (Fig. 1c). Additionally, some Cas12a showed efficient cis-cleavage but poor trans-cleavage activity (FnCas12a, Mb2Cas12a, PrCas12a), and vice versa (AsCas12a, BoCas12a, BsCas12a) (Fig. 1c-f). These comprehensive results unveiled several new combinations of crRNA:Cas12a orthologs for developing robust tools for diagnostics and gene-editing.

\section{Non-canonical crRNA affects Cas12a thermal stability}

Derived from mesophilic bacterial species, many of these Cas12a proteins have been repurposed for genome editing $(5,17-24)$. LbCas12a, AsCas12a, and FnCas12a have been most widely used in vitro and in vivo applications, including gene editing in plants, insects, and mammalian cells. They exhibit various levels of editing efficiency under different temperatures ranging from $22^{\circ} \mathrm{C}$ to $42^{\circ} \mathrm{C}(27,28)$. For instance, Merker et. al. showed that a mutated version of LbCas12a named ttLbCas12a exhibited enhanced temperature tolerant gene-editing activity and worked robustly at $22^{\circ} \mathrm{C}$ in Arabidopsis thaliana (28). Fascinated by these observations, we sought to understand whether noncanonical crRNAs could impact thermal stability of Cas12a, which subsequently could be useful for engineered guide RNA for nucleic acid detection and gene editing purposes. We, therefore, carried out differential scanning fluorimetry (DSF) of 22 Cas12a orthologs against 9 distinct groups of crRNAs (Fig. 2 a-g and Supplementary Fig. S6). We observed that the melting temperature, Tm, of the binary complex of Cas12a (crRNA:Cas12a) such as AsCas12a, CMaCas12a, PcCas12a, LbCas12a, BoCas12a, and BfCas12a did not differ from its apo form (Supplementary Fig. S6). On the other hand, TsCas12a, ArCas12a, and ErCas12a showed an increase in melting temperature in binary complex compared to their apo form (Fig. 2a-f). Surprisingly, non-canonical crRNAs such as one derived from group 6 had a tremendous effect on TsCas12a thermal stability in which its melting temperature increased by approximately $6^{\circ} \mathrm{C}$ from $44^{\circ} \mathrm{C}$ (apo) to $50^{\circ} \mathrm{C}$ (crRNA: Cas12a binary complex). 
medRxiv preprint doi: https://doi.org/10.1101/2021.07.21.21260653; this version posted July 22, 2021. The copyright holder for this preprint (which was not certified by peer review) is the author/funder, who has granted medRxiv a license to display the preprint in perpetuity. It is made available under a CC-BY-NC-ND 4.0 International license .

\section{Cas12a can recruit segments of crRNA}

The above observations allowed us to carefully examine sequences of crRNAs that are crucial for binding to Cas12a and executing cis- and trans-cleavage. Despite the various level of amino acid sequence identity among these Cas12a proteins, their complimentary mature crRNAs all share identical stem left and stem right sequences with the difference in the loops connecting them (Fig 1b). Previous studies on Cas12a structures and Cas12a-crRNA binding interactions showed that some nucleotides within the hairpin loops do not interact with amino acids within Cas12a (29-33). It is desirable to further investigate and determine fundamental components of the crRNA scaffold sequence that participate in crRNA-Cas $12 a$ binding and cleavage. By using trans-cleavage reporter assay to monitor Cas12a performance, we designed multiple truncated versions of crRNA (referred to as $\alpha, \beta, \gamma, \delta, \varepsilon, \zeta$, and $\psi$ ) targeting GFP gene fragment (Fig. 3). Truncated crRNAs either missing the stem left or stem right exhibited no observable fluorescence signal for AsCas12a, ErCas12a, and LbCas12a (Fig. 3a, c, e). Interestingly, AsCas12a showed a substantial fluorescence signal when combined with $\operatorname{crRNA}(\zeta)$ and $\operatorname{crRNA}(\Psi)$ (Fig. 3a), which do not contain the first 5 nucleotides and the loop, respectively.

From the trans-cleavage data, we speculated that sequence changes in the canonical loop region are not necessarily crucial for the protein's functionality but can be engineered for enhanced collateral cleavage efficiency. To investigate this hypothesis and to test the protein's ability to recruit segments of the crRNA, combinations of truncated crRNAs were added in increasing concentration (50 nM, $100 \mathrm{nM}$, and $500 \mathrm{nM})$ to complex with a constant concentration of Cas12a (50 nM) (Fig. 3b, d, f). Regarding LbCas12a, some signal was observed with high concentrations of the $\operatorname{crRNA}(\alpha+\varepsilon)$ or $\operatorname{crRNA}(\alpha+\beta)$, indicating the activation of the protein collateral activity (Fig. 3f). The AsCas12a exhibited much more robust trans-cleavage activity in which the fluorescence signal was comparable to the WT crRNA when a high concentration of truncated crRNAs was supplied (Fig. 3b). Notably, crRNA $(\alpha+\varepsilon)$ :ErCas12a and $\operatorname{crRNA}(\alpha+\beta)$ :ErCas12a mirrored the cleavage activity of wild-type complex, even at the same concentration (Fig. $3 d$ ). These results corroborate a previous study where crRNA with a minimized scaffold region displayed protein binding and led to efficient cis-cleavage (34). However, the findings somewhat contradicted with this study in which AsCas12a was shown to maintain robust cis-cleavage with split crRNA that was truncated at least 10 nucleotides on the 5 '-end of the crRNA. Although the trans-cleavage activity was not investigated in that study, we speculate that these truncated versions of crRNA might work in a target sequencespecific manner or high concentrations (3-5 $\mu \mathrm{M})$ of split crRNAs used may shift the equilibrium to binding Cas. We also observed that the combination $\operatorname{crRNA}(\alpha+\varepsilon)$ lacking the loop segment outperformed those which, when combined, form a complete mature crRNA $(\alpha+\beta$ and $\gamma+\delta)$ (Fig. 3b, d, f). These phenomena indicate that this loop region can be engineered to increase the overall functionality of the Cas12a proteins. Regarding the cis-cleavage activity of these truncated crRNAs, we found that they induced cutting of dsDNA for crRNA $(\alpha+\varepsilon)$ or crRNA $(\alpha+\beta)$, but their efficiency was reduced compared to wildtype complex (Fig. 3g,h). The discrepancy between the cis- and trans-cleavage activities, 
medRxiv preprint doi: https://doi.org/10.1101/2021.07.21.21260653; this version posted July 22, 2021. The copyright holder for this preprint (which was not certified by peer review) is the author/funder, who has granted medRxiv a license to display the preprint in perpetuity. It is made available under a CC-BY-NC-ND 4.0 International license .

for example, in the case of ErCas12a, needs further investigation to draw mechanistic insights into how truncatedcrRNAs are recruited and bind to the dsDNA target.

\section{A combinatorial approach to clinical validation of SARS-CoV-2 detection}

Through combinatorial screenings of trans-cleavage of 22 Cas12a orthologs, we observed that ErCas12a, TsCas12a, BsCas12a, and BoCas12a showed robust transcleavage activity in combination with both canonical and non-canonical crRNAs (Fig. 1d$\mathrm{f}$ and Supplementary Fig. S3). Additionally, their less restrictive PAM requirements compared to LbCas12a and AsCas12a make them suitable candidates for nucleic acid detection. We wondered if these Cas12a effector proteins can distinguish a SARS-CoV2 variant of concern, B.1.1.7 lineage, which was first identified in the U.K. (also known as Alpha variant), from its wild-type original variant. The standard method for detecting B.1.1.7 variant is the S-gene target failure (SGTF) test, wherein the RT-qPCR fails to detect the S-gene due to the 6-base deletions in codons H69-V70. As a proof of concept, we designed two guide RNAs for ErCas12a targeting a region encoding the spike protein of the virus. One guide RNA is compatible with the wild-type $\mathrm{S}$ gene, and the other targets the same region of the B.1.1.7 S gene bearing a 6-base deletion (Supplementary Fig. S7). One significant difference is the PAM sequence, with the B.1.1.7 crRNA containing the preferred YTTN sequence for ErCas12a (Fig. 4a). We performed a ReverseTranscription-Loop-mediated isothermal amplification (RT-LAMP) step with either wildtype SARS-CoV-2 or B.1.1.7 variant genomic RNA (obtained from BEl resources) (3, 10, 35). We proceeded to detect the amplicons with the crRNAs (henceforth referred to as crS-WT and crS-B.1.1.7) to test each of the Cas12a specificity. Within a 30-minute run from the trans-cleavage reporter assay, a 160-fold change in fluorescence signal compared to the non-template control (NTC) control was observed for the crS-B.1.1.7 targeting positive B.1.1.7 samples for all Cas12a, indicating robust specificity (Fig. $4 b, d, f, h, j, l)$. In the case of positive wild-type SARS-CoV-2, we observed some background activity from the crS-B.1.1.7 when complexed with AsCas12a, TsCas12a, BsCas12a, and BoCas12a, suggesting their various level of tolerance towards sequences mismatches (Fig. 4c,e,g,l,k,m). On the other hand, LbCas12a and ErCas12a demonstrated minimal to no background fluorescence with crS-B.1.1.7 targeting wild-type SARS-CoV-2 gRNA (Fig. 4f,g,j,k). These results, along with PAM preference, enabled us to select ErCas12a for $\mathrm{S}$ gene detection in patient samples. This finding validates the use of ErCas12a, TsCas12a, BsCas12a, and BoCas12a (in addition to LbCas12a and AsCas12a) for potential diagnostic applications, with more flexibility in temperature and PAM requirements.

We proceeded to validate their detection capabilities in patient samples while comparing WT to non-canonical crRNA. First, primers were designed and optimized for RT-LAMP reaction to amplify $\mathrm{N}$ and $\mathrm{S}$ segments of the genomic SARS-CoV-2 RNA $(3,4,10,35)$. Once amplified, $\mathrm{N}$ gene segments were detected with a series of ErCas12a, TsCas12a, BsCas12a, and BoCas12a with both WT and non-canonical crRNAs. S gene segments were verified using ErCas12a with both WT and B.1.1.7 crRNA, and finally, a quality control check of RNase P with LbCas12a. In total 50 nasopharyngeal swabs, 20 tracheal aspirates, and 45 saliva samples were validated with $96.5 \%$ accuracy (Fig. 5a-c, Table 1 , 
medRxiv preprint doi: https://doi.org/10.1101/2021.07.21.21260653; this version posted July 22, 2021. The copyright holder for this preprint (which was not certified by peer review) is the author/funder, who has granted medRxiv a license to display the preprint in perpetuity. It is made available under a CC-BY-NC-ND 4.0 International license .

Supplementary Fig. S1). In some cases, non-canonical crRNA outperformed WT detection, such as the case with ErCas12a combined with CMacrRNA (Fig. 5d). Though not enhanced in the case of BoCas12a, BsCas12a, and TsCas12a with non-canonical crRNAs, we observed their flexibility in adapting to changes in the crRNA sequence (Fig. $5 e-g)$. All samples were also confirmed with RT-qPCR, with a Ct standard of $\leq 40.0$ to be considered a positive sample. In the failed detection instances (4 false negatives), all failed samples were nasopharyngeal swabs with a higher Ct value between 35-39 and it was expected that the RT-LAMP reaction failed, likely because these samples were obtained sometime in May 2020 and had undergone multiple freeze-thaw cycles. Interestingly, out of 50 nasopharyngeal swabs, we identified 3 swabs that detected positive for the B.1.1.7 lineage. Finally, we did not observe any false positives in our assay, indicating high specificity.

\section{Discussion}

The COVID-19 pandemic in the United States seems to be under control with increased testing, vaccinations, and public response to official guidelines. However, many parts of the world are facing difficulties getting access to essential resources as a result of the COVID-19 surge $(36,37)$. Additionally, preventative measures should be kept in place to counteract future outbreaks with the emerging variants of concern. One such method is surveillance testing, which has been shown to improve early detection and response (1, 38, 39). CRISPR-based diagnostic platforms have been gaining attraction and progressively advancing in the last two years for this purpose. The recent development of CRISPR-Cas detection systems focuses on a next-generation diagnostic test that can outperform the gold standard RT-qPCR method in terms of cost, simplicity, and time (3, $4,6,12,13,40$ ). Namely, the STOPCovid (SHERLOCK testing in one pot) combines a straightforward magnetic-based extraction of SARS-CoV-2 and a thermostable AapCas $12 b$ into an all-in-one detection reaction at a single temperature (12). This method exhibits a sensitivity of $93.1 \%$ and greatly reduces carryover contamination. While these existing technologies rely on a handful of Cas12a, Cas12b, and Cas13a orthologs with robust trans-cleavage activity, a myriad of CRISPR-Cas systems remain unexplored. In an attempt to expand the diagnostic toolbox with a focus on Cas12a, we surveyed 22 functional Cas12a orthologs and found that BoCas12a, BsCas12a, ErCas12a, and TsCas12a demonstrated a comparable collateral cleavage ability to the existing LbCas12a and AsCas12a. Our comprehensive combinatorial data presented in this report identified several novel ortholog combinations that can be applied for detection and gene editing applications.

We carried out the phylogenetic analyses of these Cas12a and noted that the scaffold region of the canonical crRNA shares highly similar sequences with identical stem-left and stem-right regions. This observation corroborates a previous study in which the same phenomenon was seen $(21,24,25)$. Teng et. al. optimized the loop region between the stem-left and stem-right sections of the crRNA scaffold for enhanced gene editing purposes (21). Using biochemical assays in a combinatorial approach, we demonstrated that changes in the sequence of this loop region can be tolerated by Cas $12 a$. We discovered that this region, though not necessary, can be engineered for enhanced trans- 
medRxiv preprint doi: https://doi.org/10.1101/2021.07.21.21260653; this version posted July 22, 2021. The copyright holder for this preprint (which was not certified by peer review) is the author/funder, who has granted medRxiv a license to display the preprint in perpetuity. It is made available under a CC-BY-NC-ND 4.0 International license .

cleavage activity. One such example is non-canonical crRNA derived from the CRISPR direct repeats of Candidatus Methanomethylophilus alvus Mx1201 which outperformed canonical crRNA when complexed with ErCas12a. In fact, this combinatorial method has been employed for the development of the STOPCovid technology in which an unorthodox sgRNA scaffold derived from another bacterial species, Alicyclobacillus acidoterrestris, was complexed with AapCas12b (from Alicyclobacillus acidiphilus) (12). We further expanded this method with a combination of 22 Cas 12a and 9 distinct groups of crRNAs to investigate their performance such as cis-cleavage, collateral cleavage, and thermal stability. Additionally, we verified Tkach et. al. on the effects of truncated crRNA on the Cas12a cis-cleavage ability and discovered that some Cas12a can recruit different segments of truncated crRNA. The split crRNA:Cas12a complex proved to be substantial in its trans-cleavage activity, specifically ErCas12a and AsCas12a. Notably, the crRNA $(\alpha+\varepsilon)$ composite lacking the loop region displayed the most comparable cis- and trans-cleavage activity to WT crRNA, suggesting there is a paragon of crRNA structure that will lead to optimized detection.

As a proof of concept of cCRISPR assay, we validated the detection capabilities of BoCas12a, BsCas12a, ErCas12a, and TsCas12a with both canonical and non-canonical crRNA in clinical samples. In tandem with the combinatorial detection of the SARS-CoV$2 \mathrm{~N}$ gene, we also utilized the high specificity of ErCas12a to further develop an assay that can recognize SARS-CoV-2 B.1.1.7 lineage. We tested 45 saliva, 50 nasopharyngeal swabs, and 20 tracheal aspirates. Out of 115 patient samples, we detected no false positives and 4 false negatives from nasopharyngeal swabs, resulting in $96.5 \%$ accuracy. Three positive nasal samples were detected with B.1.1.7 variants. These samples were obtained from the University of Florida Clinical and Translational Science Institute (CTSI) and Boca Biolistics in May 2020, long before the B.1.1.7 became a variant of concern.

Here we report multiple findings that have the potential to further improve next-generation CRISPR-based diagnostics. One instance being the engineering capability of crRNA regarding loop sequence, truncation, and non-canonical combinations. Also presented is robust trans-cleavage in BoCas12a, BsCas12a, ErCas12a, and TsCas12a for diagnostics with both WT and non-canonical crRNA. Finally, SARS-CoV-2 detection and variant determination are achieved with high accuracy. Some challenges in these approaches are the requirement of an RT-LAMP pre-amplification step prior to the CRISPR detection reaction. Although we highlighted the enhanced activity of 22 Cas $12 a$ with non-canonical crRNAs, we believe there is still much room for optimization. Particularly, studies on PAM identification, crRNA sequence optimization, specificity determination, and structural and mechanistic studies will advance sensitive and specific combinatorial ortholog detection technologies and enable robust gene-editing tools.

\section{Materials and Methods}

\section{Phylogenetic analysis of Cas12a and mature crRNA orthologs}

Protein sequences of 23 Cas $12 a$ and their corresponding mature crRNA orthologs were retrieved from previous studies and compiled into a collection in Geneious Prime. The 
medRxiv preprint doi: https://doi.org/10.1101/2021.07.21.21260653; this version posted July 22, 2021. The copyright holder for this preprint (which was not certified by peer review) is the author/funder, who has granted medRxiv a license to display the preprint in perpetuity. It is made available under a CC-BY-NC-ND 4.0 International license .

collection was then subject to multiple alignments with MUSCLE to generate phylogenetic clustering. The percent identities were extracted from Geneious Prime and plotted in Graphpad Prism 9.0. Alignment of crRNA orthologs was performed using Clustal Omega and visualized in Geneious.

\section{Plasmid construction}

A total of 23 proteins were expressed using the sample procedures described below. Except for plasmids expressing LbCas12a, AsCas12a, FnCas12a, and MbCas12a obtaining from Addgene (a gift from Zhang lab and Doudna lab)(25, 41, 42), a total of 19 plasmids containing human codon-optimized Cas12a genes were obtained from Addgene (a gift from Zhang lab, Ekker Lab, and Li Lab)(21, 24, 25, 43), PCR amplified using Q5® hot start high-fidelity DNA polymerase (New England Biolabs, Catalog \#M0493S), and subcloned into a bacterial expression vector (Addgene plasmid \#29656, a gift from Scott Gradia). The product plasmids were then transformed into Rosetta ${ }^{\text {TM}(D E 3) p L y s S ~}$ Competent Cells (Millipore Sigma, Catalog \#70956) following the manufacturer's protocols. For LbCas12a, AsCas12a, FnCas12a, and MbCas12a, protein expression plasmids were obtained from Addgene and used directly for protein expression.

\section{Protein expression and purification}

For protein expression, individual colonies were picked and inoculated in $10 \mathrm{~mL}$ LB broth (Fisher Scientific, Catalog \#BP9723-500) for 12 hours. The culture was then transferred to a $1.5 \mathrm{~L}$ TB broth mix for scale-up and grown until an OD600 $=0.6-0.8$. The culture was placed on ice for 45 minutes to 1 hour prior to the addition of Isopropyl $\beta$ - $d-1$ thiogalactopyranoside (IPTG) to a final concentration of $0.5 \mathrm{mM}$. The culture was then continued to grow overnight at $16^{\circ} \mathrm{C}$ for $14-18$ hours.

Cell pellets were collected by centrifuging the overnight culture at 10,000xg for 5 minutes. The cells were then resuspended in lysis buffer $(500 \mathrm{mM} \mathrm{NaCl}, 50 \mathrm{mM}$ Tris- $\mathrm{HCl}, \mathrm{pH}=$ 7.5, $20 \mathrm{mM}$ Imidazole, $0.5 \mathrm{mM}$ TCEP, $1 \mathrm{mM}$ PMSF, $0.25 \mathrm{mg} / \mathrm{mL}$ Lysozyme, and DNase I). The cell mixture was subjected to sonication followed by centrifugation at $39800 \mathrm{xg}$ for 30 minutes. The cell lysate was filtered through a $0.22 \mu \mathrm{m}$ syringe filter (Cytiva, Catalog \#9913-2504) and then run through into 5 ml Histrap FF (Cytiva, Catalog \#17525501, $\mathrm{Ni}^{2+}$ was stripped off and recharged with $\mathrm{Co}^{2+}$ ) pre-equilibrated with Wash Buffer A (500 mM $\mathrm{NaCl}, 50 \mathrm{mM}$ Tris- $\mathrm{HCl}, \mathrm{pH}=7.5,20 \mathrm{mM}$ Imidazole, $0.5 \mathrm{mM}$ TCEP) connected to BioLogic DuoFlow $^{\mathrm{TM}}$ FPLC system (Bio-rad). The column was eluted with Elution Buffer B (500 $\mathrm{mM} \mathrm{NaCl}, 50 \mathrm{mM}$ Tris- $\mathrm{HCl}, \mathrm{pH}=7.5,250 \mathrm{mM}$ Imidazole, $0.5 \mathrm{mM}$ TCEP). The eluted fractions were pooled together and transferred to a $10 \mathrm{kDa}-14 \mathrm{kDa}$ MWCO dialysis bag. Homemade TEV protease (plasmid was obtained as a gift from David Waugh, Addgene \#8827, and purified in-house)(44) was added to the bag, submerged in Dialysis Buffer (500 mM NaCl, $50 \mathrm{mM}$ HEPES, pH 7, $5 \mathrm{mM} \mathrm{MgCl}_{2}, 2 \mathrm{mM}$ DTT) and dialyzed at $4^{\circ} \mathrm{C}$ overnight.

The protein mixture was taken out of the dialysis bag and concentrated down to around $10 \mathrm{~mL}$ using a $30 \mathrm{kDa}$ MWCO Vivaspin ${ }^{\circledR} 20$ concentrator. The concentrate was then 
medRxiv preprint doi: https://doi.org/10.1101/2021.07.21.21260653; this version posted July 22, 2021. The copyright holder for this preprint (which was not certified by peer review) is the author/funder, who has granted medRxiv a license to display the preprint in perpetuity. It is made available under a CC-BY-NC-ND 4.0 International license .

equilibrated with $10 \mathrm{~mL}$ of Wash Buffer C (150 mM NaCl, $50 \mathrm{mM} \mathrm{HEPES,} \mathrm{pH} \mathrm{=} \mathrm{7,} 0.5 \mathrm{mM}$ TCEP) prior to injecting into $1 \mathrm{~mL}$ Hitrap Heparin HP column pre-equilibrated with Wash Buffer $\mathrm{C}$ operated in the BioLogic DuoFlow ${ }^{\mathrm{TM}}$ FPLC system (Bio-rad). The protein was eluted from the column by running a gradient flowrate that exchanges Wash Buffer $\mathrm{C}$ and Elution Buffer D (2000 mM NaCl, 50 mM HEPES, pH = 7, $0.5 \mathrm{mM}$ TCEP). Depending on how pure the protein samples were, additional size-exclusion chromatography may have been needed. In short, the eluted protein from the previous step was run through a HiLoad $^{\circledR}$ 16/600 Superdex ${ }^{\circledR}$ (Cytiva, Catalog \#28989335). The purest protein was picked from the eluted fractions, pooled together, concentrated using $30 \mathrm{kDa}$ MWCO Vivaspin $囚$ 20 concentrator, snap-frozen in liquid nitrogen, and stored at $-80^{\circ} \mathrm{C}$ until use.

\section{Nucleic acid preparation}

The dsDNA activators used for screening and investigating the trans-cleavage activity of 22 Cas12a orthologs were purchased as 40-mer oligos from Integrated DNA Technologies. The crRNA sequences used for screening were purchased as ssDNA oligos with the T7 promoter sequence. The ssDNA was then annealed with the T7 complementary sequence followed by in vitro transcription to produce crRNA. For detection of patient samples, synthetic crRNAs were purchased from Integrated DNA Technologies.

\section{Trans-cleavage reporter assay}

The experiment was carried out by pre-complexing $50 \mathrm{nM}$ Cas12a and $62.5 \mathrm{nM}$ crRNA in 1X NEBuffer ${ }^{\mathrm{TM}} 2.1$ (New England Biolabs) at $37^{\circ} \mathrm{C}$ for 15 minutes. The mixture was then transferred to a medium-binding 384-well plate (FLUOTRAC ${ }^{\mathrm{TM}}$ 200, Greiner One) with $250 \mathrm{nM}$ fluorophore-quencher reporter and nucleic acid activator to a final volume of 50 $\mu \mathrm{L}$. The plate was immediately placed in BioTek Synergy 2 (Agilent) for fluorescence measurements. Fluorescence intensity for a FAM reporter was measured at wavelengths $\lambda_{\text {ex: }}$ 483/30 nm and $\lambda_{\mathrm{em}}$ : 530/30 nm every 2.5 minutes for one hour. For trans-cleavage reaction involving truncated crRNA, the crRNA:Cas $12 \mathrm{a}$ was complexed at $37^{\circ} \mathrm{C}$ for 30 minutes.

\section{In vitro cis-cleavage assay}

Combinatorial investigation of crRNA with each Cas12a was carried out by mixing crRNA, Cas12a, and dsDNA target to a final concentration of $100 \mathrm{nM}: 50 \mathrm{nM}: 6.15 \mathrm{nM}$ in 1X NEBuffer ${ }^{\mathrm{TM}}$ 2.1. The mixing was performed in a PCR 96-well plate (Applied Biosystems) in the automated Opentrons OT-2 robot and incubated at $37^{\circ} \mathrm{C}$ for 30 minutes in the robot thermal module. Proteinase $\mathrm{K}$ was added to the mixture to quench the reaction. The cleavage product was then analyzed in $1 \%$ agarose gel pre-stained with GelRed $囚$ dye (Biotium).

The above protocol was applied for all Cas12a except for PdCas12a due to its decreased reaction with the non-canonical PAM sequence. The ribonucleoprotein complex was 
medRxiv preprint doi: https://doi.org/10.1101/2021.07.21.21260653; this version posted July 22, 2021. The copyright holder for this preprint (which was not certified by peer review) is the author/funder, who has granted medRxiv a license to display the preprint in perpetuity. It is made available under a CC-BY-NC-ND 4.0 International license .

assembled at a concentration $200 \mathrm{nM}: 200 \mathrm{nM}: 6.15 \mathrm{nM}$ of PdCas12a:crRNA:dsDNA and incubated at $37^{\circ} \mathrm{C}$ for 1 hour.

For cis-cleavage reaction involving truncated crRNA, the crRNA:Cas12a was complexed at $37^{\circ} \mathrm{C}$ for 30 minutes followed by the addition of dsDNA target and incubated at $37^{\circ} \mathrm{C}$ for 1 hour. The reaction was then quenched with proteinase $\mathrm{K}$ prior to gel electrophoresis.

\section{Differential scanning fluorimetry}

The reaction was performed by combining Cas12a and crRNA to a final concentration of $1 \mu \mathrm{M}: 2.5 \mu \mathrm{M}$ in a combination of Protein Thermal Shift ${ }^{\mathrm{TM}}$ buffer (Thermofisher) and $1 \mathrm{x}$ cleavage buffer (100 nM NaCl, $50 \mathrm{nM}$ Tris- $\mathrm{HCl}, \mathrm{pH}=7.5,1 \mathrm{mM} \mathrm{DTT}$, and $10 \mathrm{mM} \mathrm{MgCl} 2$ ). The complex was incubated at $37^{\circ} \mathrm{C}$ for 15 minutes. The product was then transferred to a PCR 96-well plate (Applied Biosystems) pre-added with Protein Thermal Shift ${ }^{\mathrm{TM}}$ dye (Thermofisher), and protein melting was carried out in the qPCR StepOne Plus system (Thermofisher) over a temperature range of $25-80^{\circ} \mathrm{C}$ with a ramp rate of $1 \% /$ second. The experiment was repeated twice with 2 replicates per experiment.

\section{Patient sample collection and extraction}

Nasopharyngeal swabs and saliva samples were obtained from the University of Florida (UF) Clinical and Translational Science Institute adhering to the guidelines approved by UF Institutional Review Board (protocol\# IRB202000781). Nucleic acids extracted from the samples were carried out in an automated Maxwell囚 RSC 16 system (Promega) using Maxwell囚 RSC Viral Total Nucleic Acid Purification Kit (Promega) for both nasopharyngeal swabs and saliva, following separate protocols from the manufacturer. For tracheal aspirate, the extraction was carried out using the Maxwell $\mathbb{R}$ RC Blood DNA Kit (Promega).

\section{RT-qPCR}

Patient samples underwent RT-qPCR to determine the $\mathrm{Ct}$ values. The RT-qPCR experiments were carried out following the CDC 2019-Novel Coronavirus (2019-nCoV) Real-Time RT-PCR Diagnostic Panel. In short, a master mix of Luna ${ }^{\circledR}$ Probe One-Step RT-qPCR 4X Mix with UDG, RNase-free water, and N1/N2/RNase P (RP) primer mix was assembled as follows:

\begin{tabular}{|c|l|c|c|c|}
\hline $\begin{array}{c}\text { Item } \\
\#\end{array}$ & $\begin{array}{c}\mathrm{N} 1 \text { gene } \\
\text { master } \\
\text { mix }\end{array}$ & $\begin{array}{c}\mathrm{N} 2 \text { gene } \\
\text { master mix }\end{array}$ & $\begin{array}{c}\text { RP gene } \\
\text { master } \\
\text { mix }\end{array}$ \\
\hline 1 & $\begin{array}{l}\text { Luna } \\
\text { with UDG }\end{array}$ & $\mathrm{N} \times 5$ & $\mathrm{~N} \times 5$ & $\mathrm{~N} \times 5$ \\
\hline 2 & RNase-free water & $\mathrm{N} \times 8.5$ & $\mathrm{~N} \times 8.5$ & $\mathrm{~N} \times 8.5$ \\
\hline 3 & Primer mix (N1/N2/RP) & $\mathrm{N} \times 1.5$ & $\mathrm{~N} \times 1.5$ & $\mathrm{~N} \times 1.5$ \\
\hline & Total Volume & $\mathrm{N} \times 15$ & $\mathrm{~N} \times 15$ & $\mathrm{~N} \times 15$ \\
\hline
\end{tabular}


medRxiv preprint doi: https://doi.org/10.1101/2021.07.21.21260653; this version posted July 22, 2021. The copyright holder for this preprint (which was not certified by peer review) is the author/funder, who has granted medRxiv a license to display the preprint in perpetuity. It is made available under a CC-BY-NC-ND 4.0 International license.

The master mixes were transferred into a 96-well plate (Applied Biosystems). The reaction was initiated by adding $5 \mu \mathrm{L}$ of the extracted patient into each well and transferring to the StepOnePlus Real-Time PCR system (Applied Biosystems) for fluorescence measurements.

\section{SARS-CoV-2 detection assay}

Extracted nucleic acid from patient samples above was proceeded to the RT-LAMP preamplification reaction. $5 \mu \mathrm{L}$ of the extracted sample was added to the WarmStart ${ }^{\circledR}$ Colorimetric LAMP 2X Master Mix with UDG to a final volume of $25 \mu \mathrm{L}$. The reaction was incubated at $62^{\circ} \mathrm{C}$ for 35 minutes. Next, $2 \mu \mathrm{L}$ of the RT-LAMP product was added to the CRISPR reaction described in the trans-cleavage assay above, except the reaction was carried out in a high throughput manner using the automated Opentrons OT2 robot. Fluorescence intensity measurements were recorded and analyzed in GraphPad Prism 9.0. 
medRxiv preprint doi: https://doi.org/10.1101/2021.07.21.21260653; this version posted July 22, 2021. The copyright holder for this preprint (which was not certified by peer review) is the author/funder, who has granted medRxiv a license to display the preprint in perpetuity. It is made available under a CC-BY-NC-ND 4.0 International license .

\section{Supplementary Materials:}

Fig. S1. Percentage identity of 23 Cas $12 a$ orthologs examined in this study.

Fig. S2. Differential scanning fluorimetry of 22 Cas12a proteins.

Fig. S3. Representative trans-cleavage reporter assay of 22 Cas12a orthologs against 9 crRNAs using reporter /56-FAM/TTATT/3IABkFQ/.

Fig. S4. The trans-cleavage activity of 22 Cas $12 a$ orthologs against 9 crRNAs using RNA reporters.

Fig. S5. The cis-cleavage activity of 22 Cas12a orthologs against 9 crRNAs using RNA reporters.

Fig. S6. Differential scanning fluorimetry of 22 Cas12a against 9 crRNAs.

Fig. S7. Sequence analysis of 191 SARS-CoV-2 B.1.1.7 lineage positive samples from GISAID against wild-type SARS-CoV-2.

Table S1. Interpretation of fold-change in fluorescence.

Table S2. PAM of Cas12a orthologs.

Table S3. Sequences of nucleic acids and proteins used in the study.

Author contributions: P.K.J and L.T.N designed the experiments. L.T.N and N.C.M performed the experiments and data analysis. L.T.N and N.C.M wrote the manuscript. The manuscript was edited by P.K.J. and revised by all members.

Acknowledgments: We are thankful for valuable advice regarding experiment setup from members of Jain Lab at the University of Florida (UF). Specifically, we thank Santosh Rananaware and Isabel Roberts for the help with patient sample extraction and buffer preparation. We are grateful to Dr. Timothy Hamerly from Dr. Rhoel Dinglasan's lab for suggestions on optimizing the DSF experiments. We also thank Dr. Cuong Nguyen, Dr. David Ostrov, Dr. Rhoel Dinglasan, and Dr. Marco Salemi for their support in obtaining the patient samples. Finally, we are grateful to the University of Florida, the UF Health Cancer Center, and the Clinical and Translational Science Institute Repository for their support. The following reagents were obtained through BEI Resources, NIAID, NIH: Genomic RNA from SARS-Related Coronavirus 2, Isolate USA-WA1/ 2020, NR-52285. Genomic RNA from SARS-Related Coronavirus 2, Isolate USA/CA_CDC_5574/2020 (Lineage B.1.1.7), NR-55244, contributed by Centers for Disease Control and Prevention.

Funding Statement: This work was supported by funds from the University of Florida (UF), the UF Herbert Wertheim College of Engineering, Florida Breast Cancer Foundation (AGR00018466), and the United States-India Science \& Technology Endowment Fund (USISTEF/COVID-I/247/2020).

Data and materials availability: All data associated with this study are in the main text and the Supplementary Materials. The expression plasmids will be soon deposited to Addgene after obtaining the required permissions.

Ethical Statement: This study was performed under the UF IRB protocol IRB202000781.

Competing interests: P.K.J. and L.T.N. are listed as inventors on patent applications related to the content of this work. 
medRxiv preprint doi: https://doi.org/10.1101/2021.07.21.21260653; this version posted July 22, 2021. The copyright holder for this preprint

(which was not certified by peer review) is the author/funder, who has granted medRxiv a license to display the preprint in perpetuity.

It is made available under a CC-BY-NC-ND 4.0 International license .

\section{References}

1. Center for Disease Control, COVID-19 Serology Surveillance Strategy (2021 https://www.cdc.gov/coronavirus/2019-ncov/covid-data/serologysurveillance/index.html\#print).

2. S. Miceli. (The National Academies of Sciences Engineering Medicine, 2020), vol. 2021.

3. Z. Ali et al., iSCAN: An RT-LAMP-coupled CRISPR-Cas12 module for rapid, sensitive detection of SARS-CoV-2. Virus Res 288, 198129 (2020).

4. J. P. Broughton et al., CRISPR-Cas12-based detection of SARS-CoV-2. Nat Biotechnol 38, 870-874 (2020).

5. J. S. Chen et al., CRISPR-Cas12a target binding unleashes indiscriminate single-stranded DNase activity. Science 360, 436-439 (2018).

6. X. Ding et al., Ultrasensitive and visual detection of SARS-CoV-2 using all-in-one dual CRISPR-Cas12a assay. Nat Commun 11, 4711 (2020).

7. J. S. Gootenberg et al., Nucleic acid detection with CRISPR-Cas13a/C2c2. Science 356, 438-442 (2017).

8. S. Jungnick et al., Detection of the new SARS-CoV-2 variants of concern B.1.1.7 and B.1.351 in five SARS-CoV-2 rapid antigen tests (RATs), Germany, March 2021. Euro Surveill 26, (2021).

9. M. J. Kellner, J. G. Koob, J. S. Gootenberg, O. O. Abudayyeh, F. Zhang, SHERLOCK: nucleic acid detection with CRISPR nucleases. Nat Protoc 14, 2986-3012 (2019).

10. X. Fang, H. Chen, S. Yu, X. Jiang, J. Kong, Predicting viruses accurately by a multiplex microfluidic loop-mediated isothermal amplification chip. Anal Chem 83, 690-695 (2011).

11. Y. Jiang et al., Detection of SARS-CoV-2 by CRISPR/Cas12a-Enhanced Colorimetry. ACS Sens 6, 1086-1093 (2021).

12. J. Joung et al., Detection of SARS-CoV-2 with SHERLOCK One-Pot Testing. $N$ Engl J Med 383, 1492-1494 (2020).

13. M. Patchsung et al., Clinical validation of a Cas13-based assay for the detection of SARS-CoV-2 RNA. Nat Biomed Eng 4, 1140-1149 (2020).

14. Food and Drug Administration, INSTRUCTIONS FOR USE Sherlock ${ }^{T M}$ CRISPR SARS-CoV-2 kit (2020 https://www.fda.gov/media/137746/download).

15. Food and Drug Administration, ACCELERATED EMERGENCY USE AUTHORIZATION (EUA) SUMMARY SARS-COV-2 RNA DETECTR ASSAY (2020 https://www.fda.gov/media/139937/download).

16. L. T. Nguyen, S. R. Rananaware, B. L. M. Pizzano, B. T. Stone, P. K. Jain, Engineered CRISPR/Cas12a Enables Rapid SARS-CoV-2 Detection. MedRxiv, (2020).

17. C. C. Campa, N. R. Weisbach, A. J. Santinha, D. Incarnato, R. J. Platt, Multiplexed genome engineering by Cas12a and CRISPR arrays encoded on single transcripts. Nat Methods 16, 887-893 (2019).

18. J. S. Gootenberg et al., Multiplexed and portable nucleic acid detection platform with Cas13, Cas12a, and Csm6. Science 360, 439-444 (2018). 
medRxiv preprint doi: https://doi.org/10.1101/2021.07.21.21260653; this version posted July 22, 2021. The copyright holder for this preprint (which was not certified by peer review) is the author/funder, who has granted medRxiv a license to display the preprint in perpetuity. It is made available under a CC-BY-NC-ND 4.0 International license .

19. S. Y. Li et al., CRISPR-Cas12a has both cis- and trans-cleavage activities on single-stranded DNA. Cell Res 28, 491-493 (2018).

20. Z. Liu et al., ErCas12a CRISPR-MAD7 for Model Generation in Human Cells, Mice, and Rats. CRISPR J 3, 97-108 (2020).

21. F. Teng et al., Enhanced mammalian genome editing by new Cas12a orthologs with optimized crRNA scaffolds. Genome Biol 20, 15 (2019).

22. T. Yamano et al., Structural Basis for the Canonical and Non-canonical PAM Recognition by CRISPR-Cpf1. Mol Cell 67, 633-645.e633 (2017).

23. H. Yue et al., Droplet Cas12a Assay Enables DNA Quantification from Unamplified Samples at the Single-Molecule Level. Nano Lett 21, 4643-4653 (2021).

24. B. Zetsche, O. O. Abudayyeh, J. S. Gootenberg, D. A. Scott, F. Zhang, A Survey of Genome Editing Activity for 16 Cas12a Orthologs. Keio J Med 69, 59-65 (2020).

25. B. Zetsche et al., Cpf1 is a single RNA-guided endonuclease of a class 2 CRISPR-Cas system. Cell 163, 759-771 (2015).

26. I. Fonfara, H. Richter, M. Bratovič, A. Le Rhun, E. Charpentier, The CRISPRassociated DNA-cleaving enzyme Cpf1 also processes precursor CRISPR RNA. Nature 532, 517-521 (2016).

27. F. Port, M. Starostecka, M. Boutros, Multiplexed conditional genome editing with Cas12a in. Proc Natl Acad Sci U S A 117, 22890-22899 (2020).

28. L. Merker, P. Schindele, H. Puchta, Using CRISPR/ttLbCas12a for in planta Gene Targeting in A. thaliana. Curr Protoc Plant Biol 5, e20117 (2020).

29. D. C. Swarts, J. van der Oost, M. Jinek, Structural Basis for Guide RNA Processing and Seed-Dependent DNA Targeting by CRISPR-Cas12a. Mol Cell 66, 221-233.e224 (2017).

30. D. C. Swarts, M. Jinek, Mechanistic Insights into the cis- and trans-Acting DNase Activities of Cas12a. Mol Cell 73, 589-600.e584 (2019).

31. D. Dong et al., The crystal structure of Cpf1 in complex with CRISPR RNA. Nature 532, 522-526 (2016).

32. P. Gao, H. Yang, K. R. Rajashankar, Z. Huang, D. J. Patel, Type V CRISPR-Cas Cpf1 endonuclease employs a unique mechanism for crRNA-mediated target DNA recognition. Cell Res 26, 901-913 (2016).

33. T. Yamano et al., Crystal Structure of Cpf1 in Complex with Guide RNA and Target DNA. Cell 165, 949-962 (2016).

34. R. Tkach et al., Efficient target cleavage by Type $\vee$ Cas12a effector programmed with split CRISPR RNA. BioRxiv, (2020).

35. T. Notomi et al., Loop-mediated isothermal amplification of DNA. Nucleic Acids Res 28, E63 (2000).

36. K. Katella. (Yale Medicine, 2021).

37. . (United Nations, Department of Economic and Social Affairs

Economic Analysis, 2020).

38. T. Meštrović. (News Medical Life Sciences, 2020).

39. J. N. Rauch et al., Rapid CRISPR-based surveillance of SARS-CoV-2 in asymptomatic college students captures the leading edge of a community-wide outbreak. MedRxiv, (2020). 
medRxiv preprint doi: https://doi.org/10.1101/2021.07.21.21260653; this version posted July 22, 2021. The copyright holder for this preprint

(which was not certified by peer review) is the author/funder, who has granted medRxiv a license to display the preprint in perpetuity.

It is made available under a CC-BY-NC-ND 4.0 International license .

40. P. Fozouni et al., Amplification-free detection of SARS-CoV-2 with CRISPRCas13a and mobile phone microscopy. Cell 184, 323-333.e329 (2021).

41. K. E. Watters, C. Fellmann, H. B. Bai, S. M. Ren, J. A. Doudna, Systematic discovery of natural CRISPR-Cas12a inhibitors. Science 362, 236-239 (2018).

42. B. Zetsche et al., Multiplex gene editing by CRISPR-Cpf1 using a single crRNA array. Nat Biotechnol 35, 31-34 (2017).

43. W. A. Wierson et al., Expanding the CRISPR Toolbox with ErCas12a in Zebrafish and Human Cells. CRISPR J 2, 417-433 (2019).

44. R. B. Kapust et al., Tobacco etch virus protease: mechanism of autolysis and rational design of stable mutants with wild-type catalytic proficiency. Protein Eng 14, 993-1000 (2001).

45. R. Lorenz et al., ViennaRNA Package 2.0. Algorithms Mol Biol 6, 26 (2011).

46. S. Elbe, G. Buckland-Merrett, Data, disease and diplomacy: GISAID's innovative contribution to global health. Glob Chall 1, 33-46 (2017).

47. Y. Shu, J. McCauley, GISAID: Global initiative on sharing all influenza data - from vision to reality. Euro Surveill 22, (2017). 
medRxiv preprint doi: https://doi.org/10.1101/2021.07.21.21260653; this version posted July 22, 2021. The copyright holder for this preprint (which was not certified by peer review) is the author/funder, who has granted medRxiv a license to display the preprint in perpetuity. It is made available under a CC-BY-NC-ND 4.0 International license .

\section{Main figures:}

a

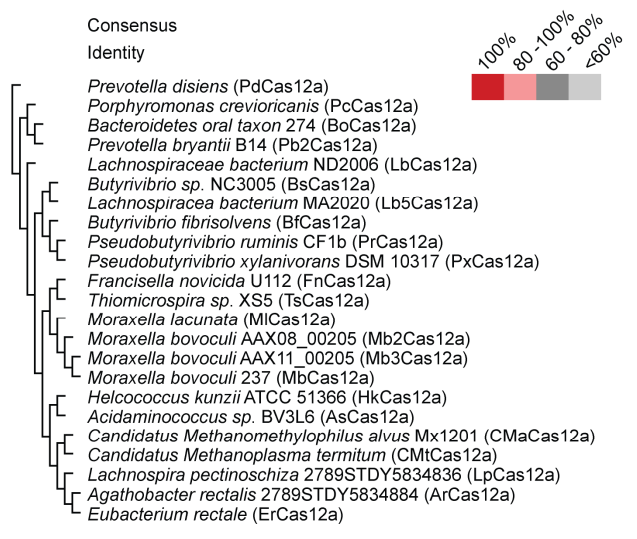

b
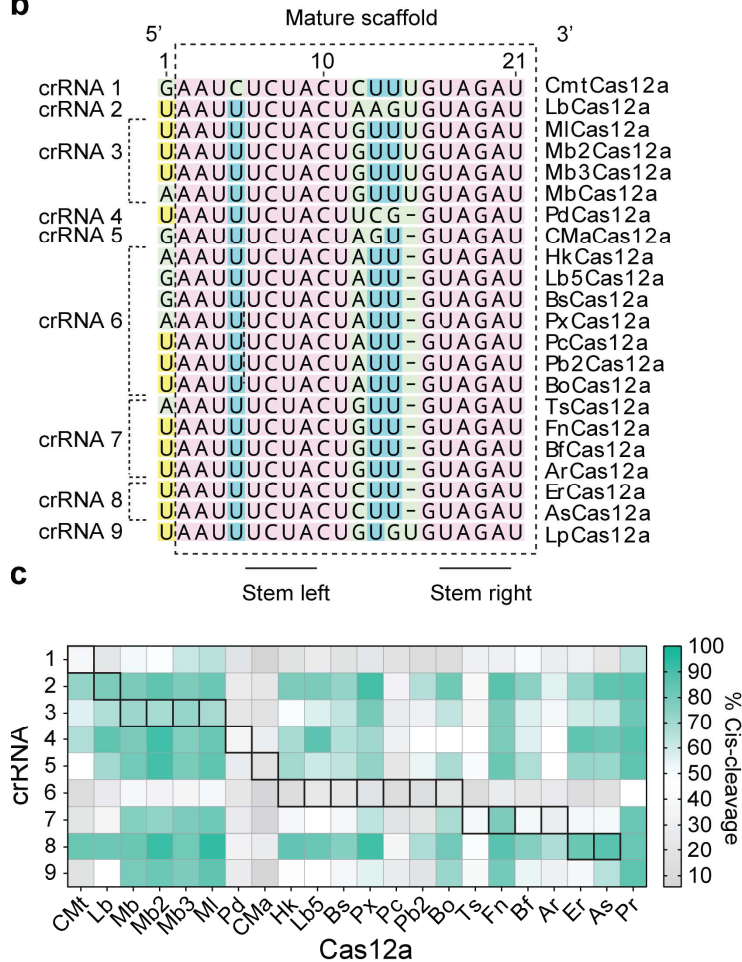

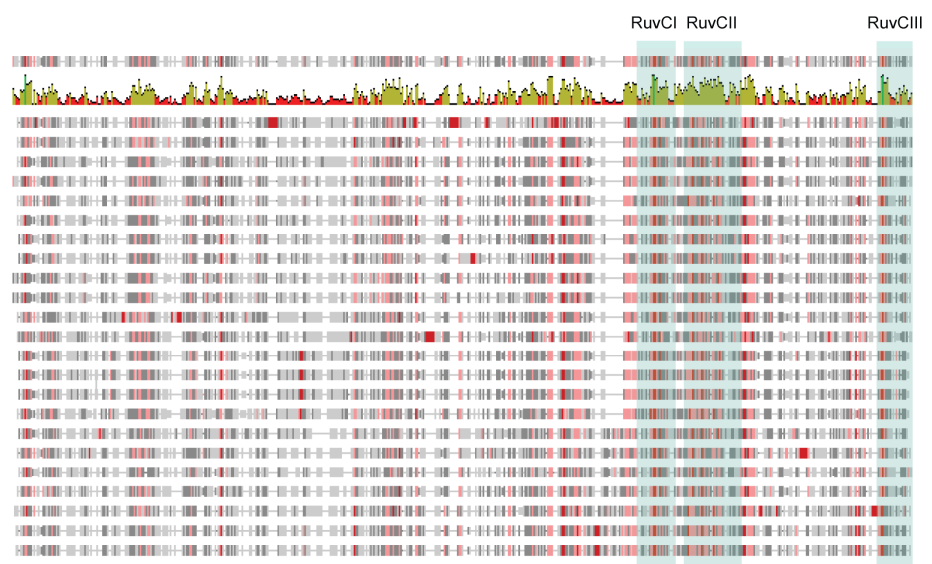

d
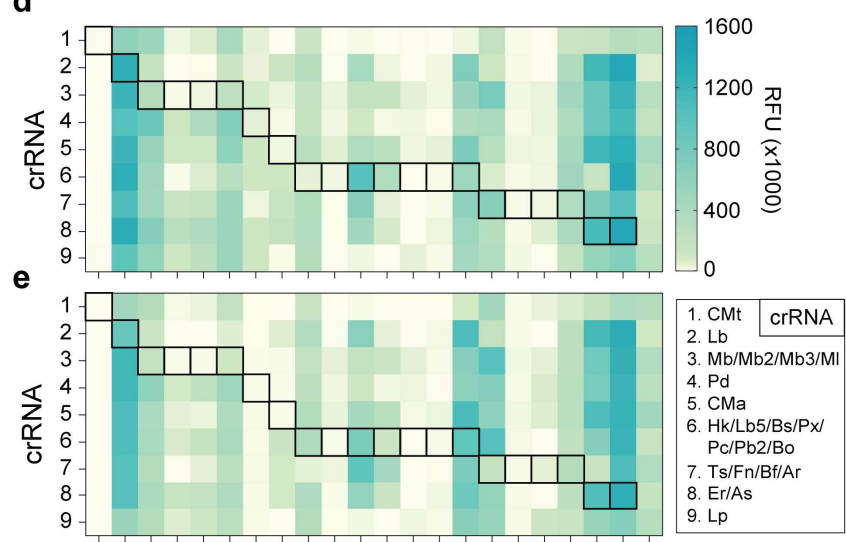

f
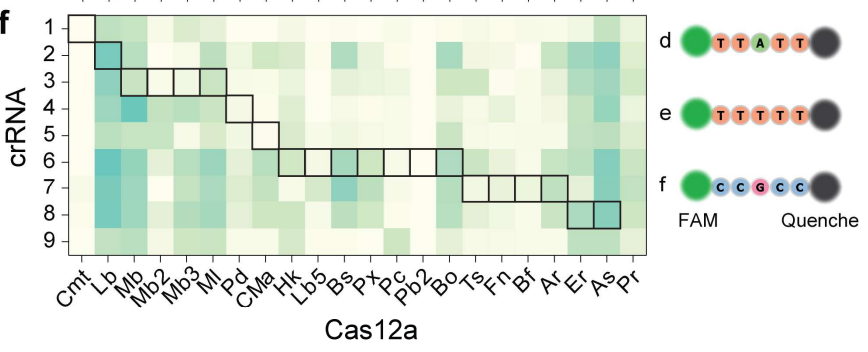

Cas12a

Figure 1. A survey of in vitro performance of Cas12a proteins. (a) Phylogenetic analysis of 23 Cas12a orthologs. Sequence alignment of Cas12a shows conserved regions of RuvC and Nuc domain. (b) Sequence alignment of mature crRNA from CRISPR direct repeats across all 23 Cas 12 a orthologs display high similarity and conserved stem-loops. To minimize the number of combinations, identical and/or similar crRNA sequences were clustered together into 9 groups. (c) Percentage of cleavage from the cis-cleavage assay. The cleavage reaction was visualized via gel electrophoresis and analyzed by ImageJ (mean, $\mathrm{n}=2$ independent experiments). (d), (e), (f) Background corrected fluorescence of 22 functional Cas12a against 9 crRNAs in a combinatorial fashion with TTATT, TTTTT, and CCGCC reporters, respectively. The fluorescence signal was collected using the trans-cleavage reporter assay at $t=20$ minutes (mean, $n=3$ independent experiments). Similarly grouped crRNA (considered wild-type) and their corresponding Cas12a proteins are highlighted in the boxes with borders. 
medRxiv preprint doi: https://doi.org/10.1101/2021.07.21.21260653; this version posted July 22, 2021. The copyright holder for this preprint (which was not certified by peer review) is the author/funder, who has granted medRxiv a license to display the preprint in perpetuity.

It is made available under a CC-BY-NC-ND 4.0 International license .

a

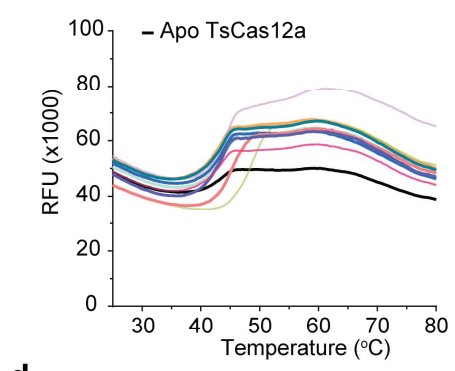

d

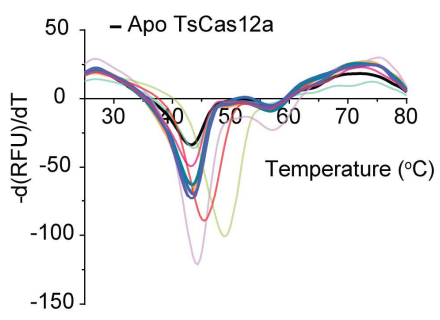

g b

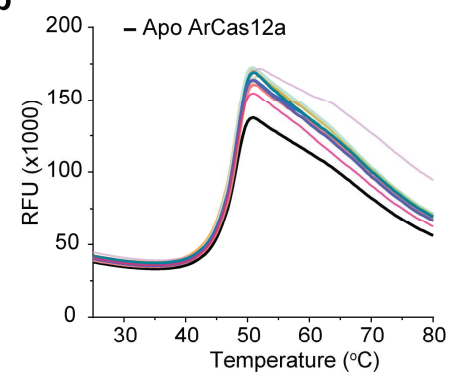

e

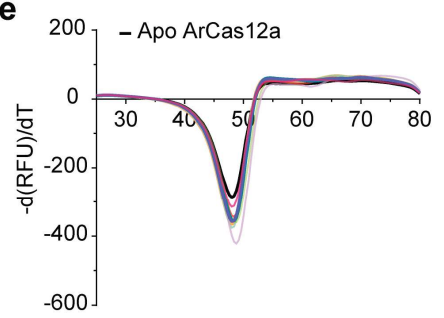

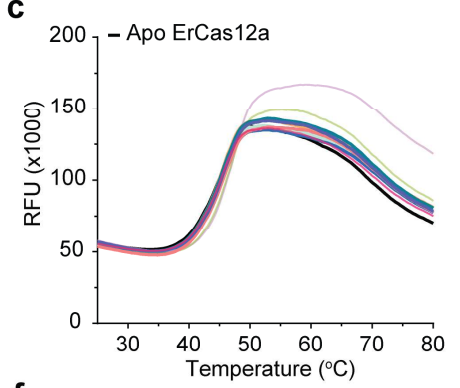

f

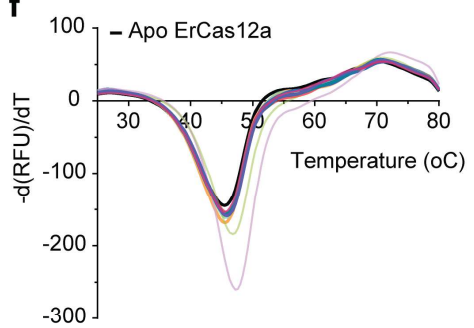

- $\mathrm{CMa}$

- CMt

- Mb/Mb2/Mb3/MI

$-\mathrm{Lp}$

$-\mathrm{Lb}$

Bo/Bs/Hk/Lb5

/Pc/Pb2/Px

- As/Er

- Ar/Bf/Ts/Fn

- Pd

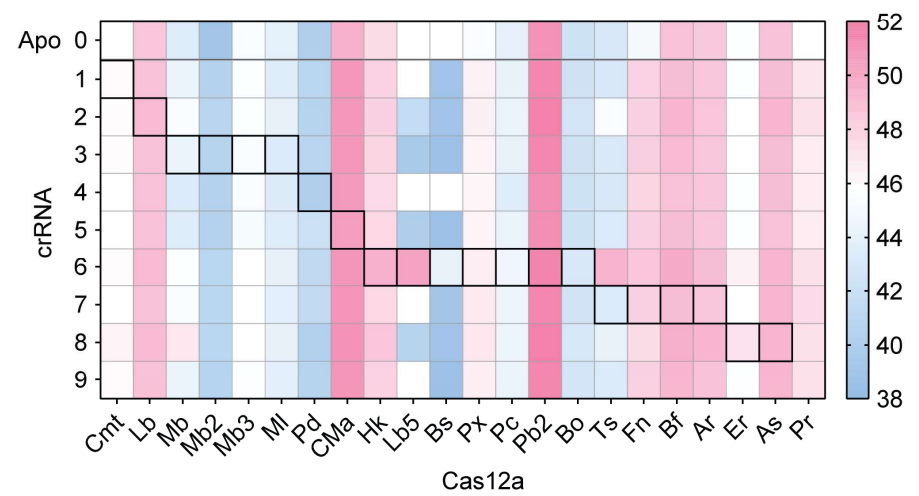

1. CMt crRNA

2. $\mathrm{Lb}$

3. $\mathrm{Mb} / \mathrm{Mb} 2 / \mathrm{Mb} 3 / \mathrm{Ml}$

4. $\mathrm{Pd}$

5. CMa

6. $\mathrm{Hk} / \mathrm{Lb} 5 / \mathrm{Bs} / \mathrm{Px} /$

$\mathrm{Pc} / \mathrm{Pb} 2 / \mathrm{Bo}$

7. $\mathrm{Ts} / \mathrm{Fn} / \mathrm{Bf} / \mathrm{Ar}$

8. $\mathrm{Er} / \mathrm{As}$

9. Lp

Figure 2. Noncanonical crRNAs increase the thermal stability of some Cas12a. (a)(f) Representation of differential scanning fluorimetry of 3 Cas12a (TsCas12a, ArCas12a, and ErCas12a), where (a), (c), and (e) represents melting curves, and (b), (d), and (f) represents the derivative of fluorescence from (a), (c), and (e), respectively (mean, $n=4$, with $n=2$ replicates per experiment over two independent experiments). For melting curves of the rest of Cas12a, refer to supplementary Figure S6. (g) Summary of thermal stability of 22 Cas $12 a$ when complexing with 9 different crRNAs. Similarly grouped crRNA (considered wild-type) and their corresponding Cas12a proteins are highlighted in the boxes with borders. The fluorescence signal presented is the mean value with a total $n=$ 4 ( $n=2$ replicates per experiment over two independent experiments). 
medRxiv preprint doi: https://doi.org/10.1101/2021.07.21.21260653; this version posted July 22, 2021. The copyright holder for this preprint (which was not certified by peer review) is the author/funder, who has granted medRxiv a license to display the preprint in perpetuity.

It is made available under a CC-BY-NC-ND 4.0 International license .
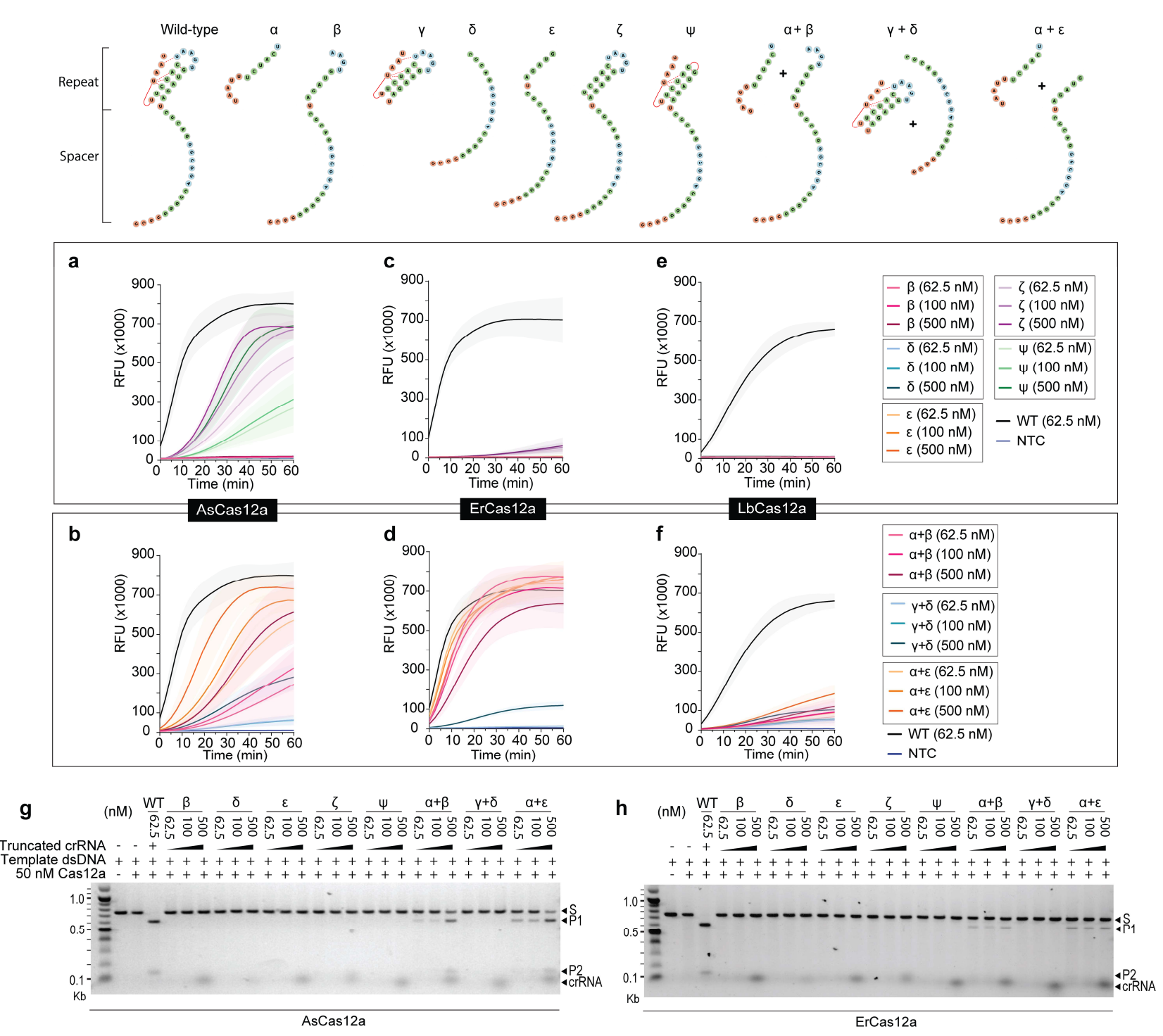

Figure 3. Part of the hairpin loop of the crRNA scaffold is not crucial for cleavage, but sequence changes can enhance the overall performance of Cas12a. RNAfold was used to predict some of the crRNA structures (45). (a), (c), and (e) Fluorescence signal of individual truncated crRNAs. (b), (d), and (f) Fluorescence signal of combined truncated crRNAs. The fluorescence was collected using the trans-cleavage reporter assay at $\mathrm{t}=20$ minutes (mean $\pm \mathrm{SD}, \mathrm{n}=3$ independent experiments). (g) and (h) ciscleavage assay of all truncated crRNAs from (a) to (f). The cis-cleavage experiment has been repeated with similar results. 
medRxiv preprint doi: https://doi.org/10.1101/2021.07.21.21260653; this version posted July 22, 2021. The copyright holder for this preprint (which was not certified by peer review) is the author/funder, who has granted medRxiv a license to display the preprint in perpetuity.
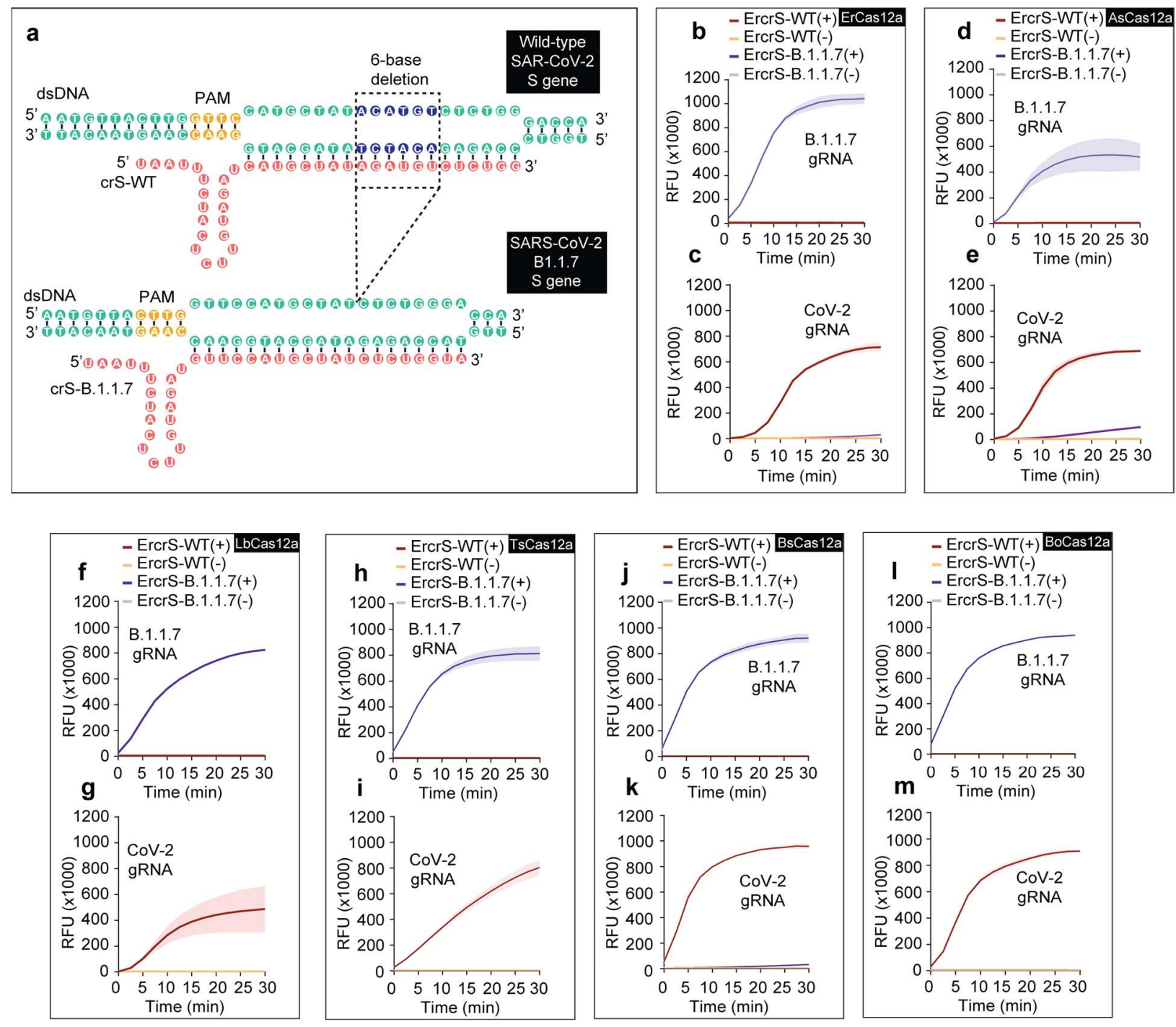

Figure 4. ErCas12a shows robust trans-cleavage and can detect SARS-CoV-2 B1.1.7 lineage. (a) Schematic of crRNA designed to target SARS-CoV-2 B.1.1.7 variant. Genomic RNA of SARS-CoV-2 B.1.1.7 lineage was amplified using RT-LAMP and detected by crRNA targeting Spike gene (S gene) bearing 6-base deletion. (b) $-(\mathbf{m})$ Fluorescence signal by trans-cleavage reporter assay for AsCas12a, LbCas12a, ErCas12a, TsCas12a, BsCas12a, and BoCas12a where (b), (d), (f), (h), (j), and (l) signify that the activator is an amplicon amplified using B.1.1.7 genomic RNA, and (c), (e), (g), $(\mathrm{i}),(\mathrm{k})$, and $(\mathrm{m})$ signify that activator is an amplicon amplified using wild-type genomic RNA SARS-CoV-2 (mean \pm SD, $n=2$ independent experiments). crS-WT(+) denotes the Cas12a in complex with ErcrRNA targeting $S$ gene of wild type SARS-CoV-2 in a positive sample (+). crS-WT(-) describes the Cas12a in complex with ErcrRNA targeting S gene of wild type SARS-CoV-2 in a negative sample (-). crS-B1.1.7(+) denotes the Cas12a in complex with ErcrRNA targeting S gene of SARS-CoV-2 B1.1.7 in B1.1.7 positive sample $(+)$. crS-B1.1.7(-) describes the Cas12a in complex with ErcrRNA targeting $S$ gene of SARS-CoV-2 B1.1.7 in B1.1.7 negative sample. 
medRxiv preprint doi: https://doi.org/10.1101/2021.07.21.21260653; this version posted July 22, 2021. The copyright holder for this preprint (which was not certified by peer review) is the author/funder, who has granted medRxiv a license to display the preprint in perpetuity.

It is made available under a CC-BY-NC-ND 4.0 International license .

a
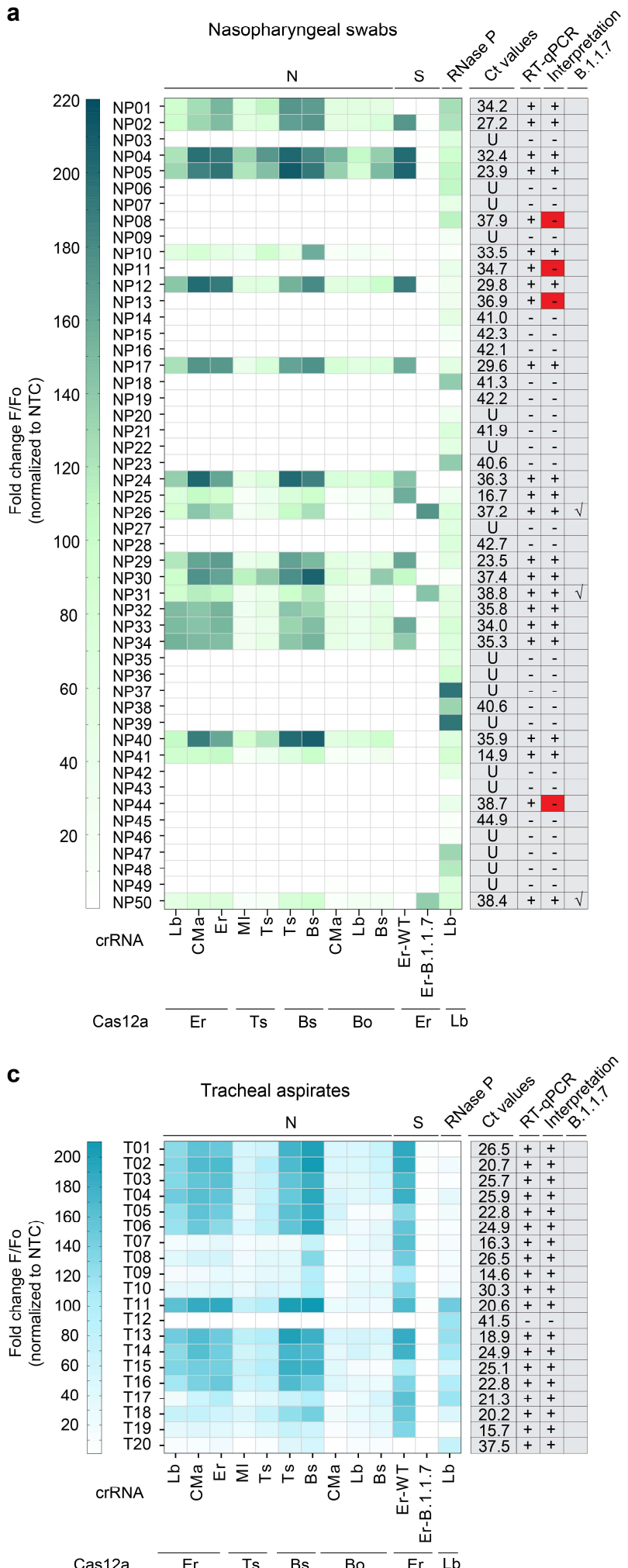

b
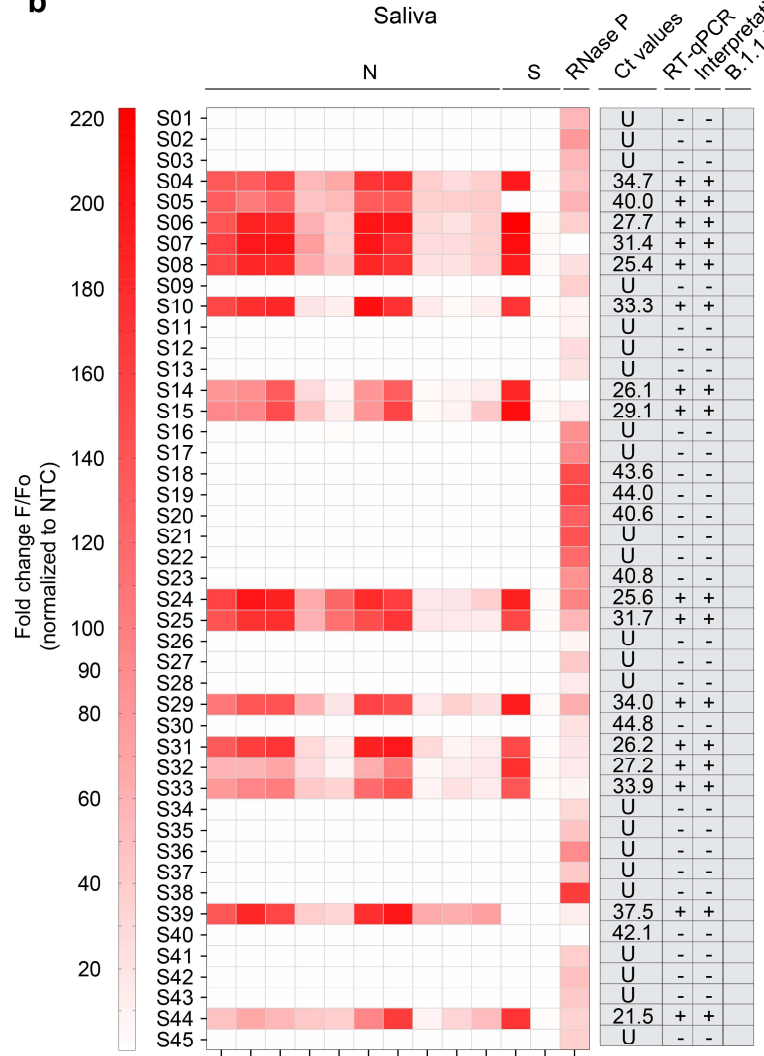

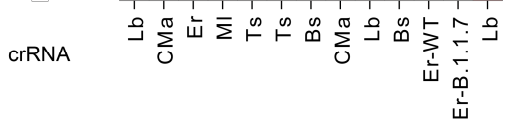

Cas12a $\overline{\mathrm{Er}} \frac{\mathrm{Ts}}{\mathrm{Bs}} \overline{\mathrm{Bo}} \frac{\mathrm{Er}}{\mathrm{Lb}}$

d
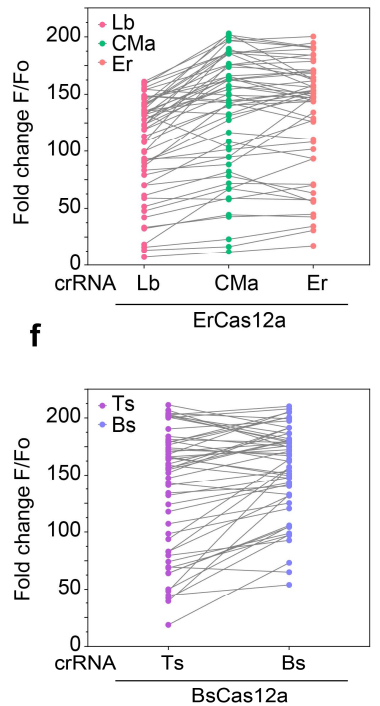

e
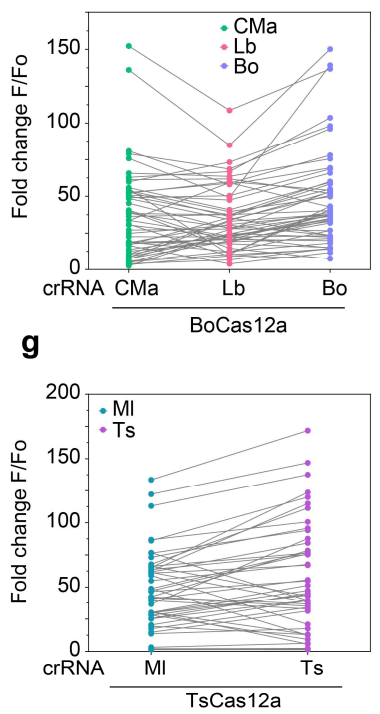
medRxiv preprint doi: https://doi.org/10.1101/2021.07.21.21260653; this version posted July 22, 2021. The copyright holder for this preprint (which was not certified by peer review) is the author/funder, who has granted medRxiv a license to display the preprint in perpetuity. It is made available under a CC-BY-NC-ND 4.0 International license .

Figure 5. Validation of patient samples using new Cas12a variants with cCRISPR assay. The four proteins ErCas12a, TsCas12a, BsCas12a, and BoCas12a with the best combination of crRNA candidates were selected and tested on patient samples. Notably, some non-canonical crRNAs exhibit enhanced trans-cleavage with higher fluorescence signals compared to the wild-type crRNA. (a), (b), and (c) CRISPR detection consisting of positive and negative SARS-CoV-2 determination and detecting B.1.1.7 variant via fluorescence reporter assay in nasopharyngeal swabs, saliva, and tracheal aspirate samples, respectively. The fluorescence shown above was taken at $t=15$ minutes, except for RNase $\mathrm{P}$ taken at $\mathrm{t}=30$ minutes. (d), (e), (f), and (g) Detection performance of ErCas12a, BsCas12a, TsCas12a, and BoCas12a with canonical and non-canonical crRNA. Clinical samples positive with $\mathrm{N}$-gene from nasopharyngeal swabs, saliva samples, and tracheal aspirates were pooled together to evaluate the combinatorial performance of these Cas12a nucleases. A single experiment was performed to simulate the real-world scenario. 
Table 1. Summary of clinical sample detection

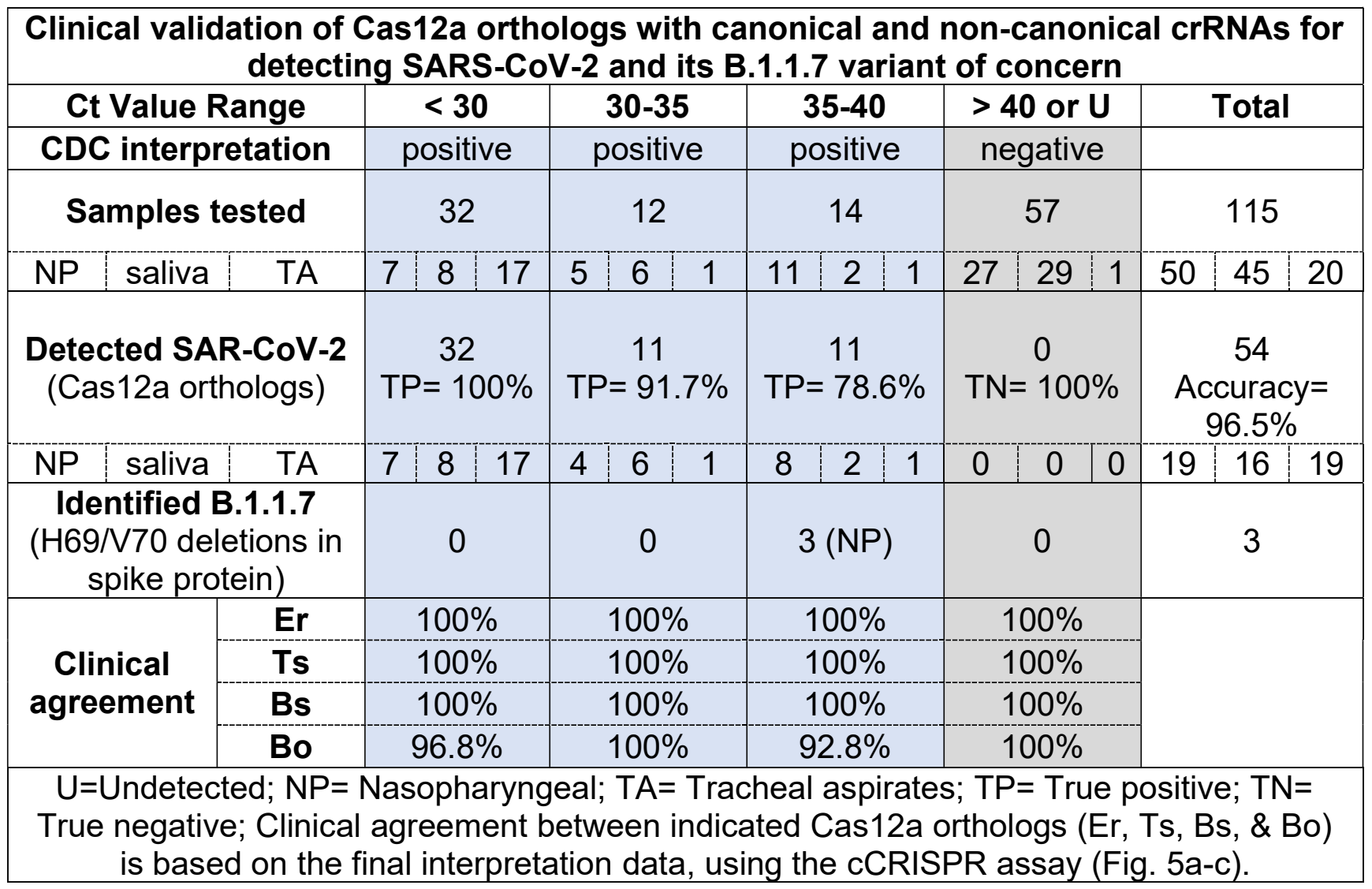

